\title{
The Association between Physical Activity and Eating Self-Regulation in Overweight and Obese Women
}

\author{
Eliana V. Carraça Marlene N. Silva Sílvia R. Coutinho Paulo N. Vieira \\ Cláudia S. Minderico Luís B. Sardinha Pedro J. Teixeira \\ Interdisciplinary Centre for the Study of Human Performance (CIPER), Faculty of Human \\ Kinetics, Technical University of Lisbon, Portugal
}

\author{
Key Words \\ Obesity · Physical activity · Negative body image investment - Depressive mood . \\ Eating behavior
}

\section{Abstract}

Objective: Successful weight management relies heavily on eating and exercise behaviors. However, little is known about the association between both on a psychosocial level. This study examined the relationship between exercise and eating regulation by exploring the mediating effects of negative body image investment and depressive mood, and their stability through time. Methods: Analyses were conducted at two different moments (12 and 36 months), involving a sample of 221 overweight/obese women (age: $37.6 \pm 7$ years; BMI: 31.6 $\pm 4.1 \mathrm{~kg} / \mathrm{m}^{2}$ ) that participated in a behavioral weight control intervention. Bivariate correlations and mediation analyses using Preacher \& Hayes resampling procedures were conducted. Results: At 12 months, negative body image investment was the only significant mediator of the exercise-eating relationship. This variable explained larger portions of the indirect effects of structured rather than lifestyle exercise on eating. At 36 months, negative investment and to a lesser extent depressive mood partially explained the exercise-eating association. Conclusions: Our findings suggest that, besides physiological effects of exercise, psychological mechanisms related to body image and mood also explain the role of physical activity as a 'gateway behavior' for improved eating regulation in overweight women. These effects appear to be stable and may help understand the key role of exercise in long-term weight management. 


\section{Introduction}

Even though Western societies are gradually more alert and sensitive to issues involving overweight and obesity, they remain highly prevalent and constitute a strong risk factor for several co-morbidities and premature death $[1,2]$. Behavioral weight loss interventions consistently result in 7-10\% reductions in body weight, but these effects are commonly reversed over time [3], which can be attributable, in part, to an insufficient understanding of the connection between two cornerstones of obesity treatment: physical activity and eating behavior. Indeed, successful weight management relies heavily on modifying both behaviors to induce an energy deficit. However, little emphasis has been placed on understanding how a change in one of these behaviors may interact with, support, or thwart the efforts to regulate the other. A clearer understanding of the mechanisms inherent to this relationship can help interventions facilitate adherence to these (and possibly other) energy balance-related behaviors, potentiate their combined effect, and hopefully improve weight loss maintenance success.

In the last few decades, several mechanisms involved in the exercise-eating behavior relationship have been explored. Some lines of research have suggested that physiological processes such as improved appetite regulation might be involved (for a review see [4]). Others have proposed that psychological mechanisms are also involved and that key selfregulatory resources are likely to be shared and even transferable between health-related behaviors [5]. The suggestion that exercise could impact long-term weight management and associated behaviors also by improving psychological variables (e.g., self-efficacy, body image, or mood) and self-regulatory resources (e.g., motivation and confidence) is wellknown [6] and is gaining empirical support. For example, Annesi and Unruh [7] found that exercise participation was associated with significant improvements in body image and mood, which in turn contributed to increased exercise attendance and weight loss. In addition, increases in general and exercise-specific autonomous motivation [5] and in exercise selfefficacy [8] have been shown to predict positive changes in eating self-regulation, supporting the existence of a motivational 'spill-over' between health behaviors important for weight management [5]. However, empirical evidence accounting for psychological processes relating exercise to improved eating self-regulation remains scarce. Within the obese population, two psychological variables that could potentially be involved in this association are body image and depressive mood $[9,10]$.

Poor body image, in particular the excessive preoccupation and investment in the management of appearance, has been confirmed as a strong correlate and even as a precursor of maladaptive eating behaviors [11-13]. Body image disturbances have also been associated with increased binge eating and other bulimic symptomatology [14-15]. On the other hand, recent evidence indicates that improving body image (especially by reducing dysfunctional investment in appearance) could contribute to a better eating self-regulation in overweight women [16].

Regular exercise participation can improve body image. Prior research clearly supports the role of exercise on body image, showing that physically active individuals present enhanced body image and related physical self-perceptions compared to sedentary controls [17]. Empirical research in the obesity field has also reported improvements in body-related satisfaction and overvaluation in previously sedentary obese women $[18,19]$. Thus, it is possible that the positive effect of regular exercise on eating self-regulation could partially arise from the relief of body image distress.

Negative emotional states can also negatively impact eating self-regulation [20]; for example, depressive symptoms have been associated with emotional eating, increased consumption of high-calorie foods, and lower intake of vegetables/fruits [21]. Negative affect 
Carraça et al.: The Association between Physical Activity and Eating Self-Regulation in Overweight and Obese Women

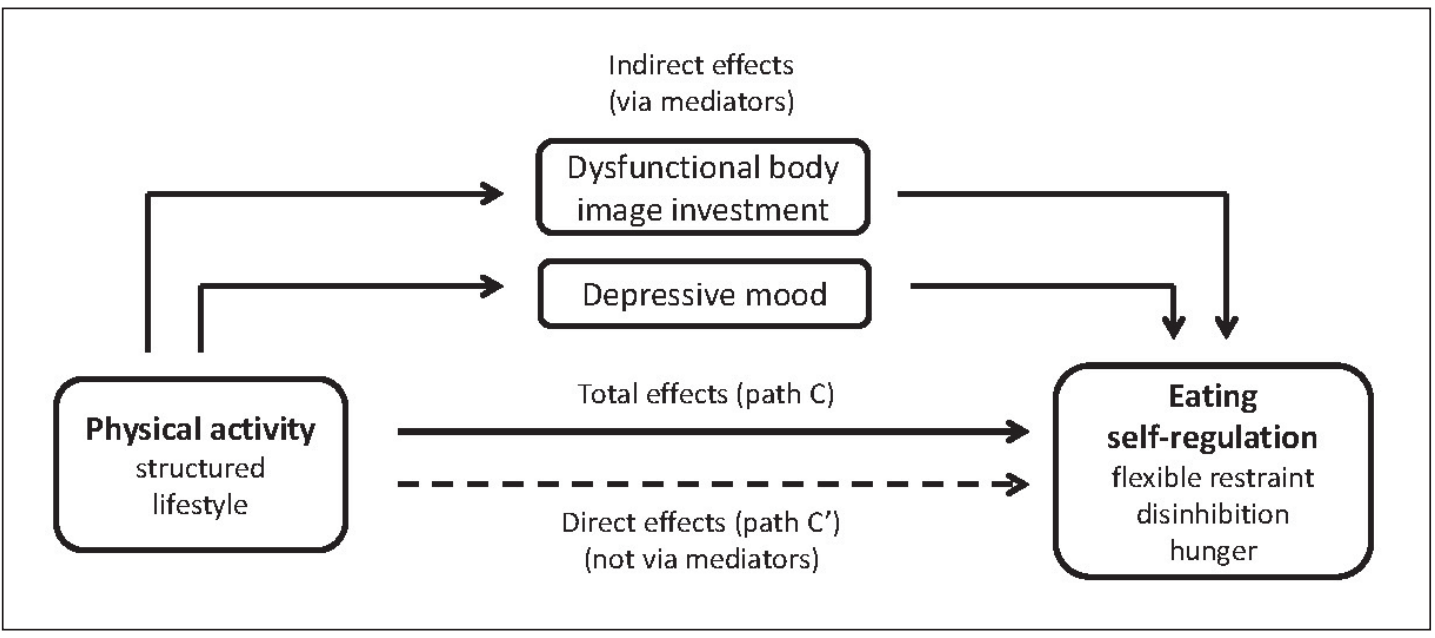

Fig. 1. Mediation models. The model includes two predictors - structured and lifestyle physical activity -, two putative mediators - negative body image investment and depressive mood -, and three outcome variables - flexible restraint, eating disinhibition and perceived hunger. This mediation model was analyzed at 12 and 36 months.

has also been shown to predict increased risk for binge eating [22] and greater eating disorder severity [23]. Conversely, there is consistent evidence that exercise is associated with positive changes in overall well-being and in specific variables such as mood and depression [24]. For example, Annesi and Unruh [7] found that exercise participation was associated with significant improvements in mood states in previously sedentary obese women. Furthermore, Annesi and Vaughn [25] recently confirmed prior propositions made by Baker and Brownell [6] suggesting that exercise-induced improvements in negative psychological states, such as depressive mood, are important mechanisms underlying the association between physical activity, eating, and weight management. Specifically, they showed that changes in depression mediated the association between exercise and eating self-efficacy in severely obese women [25]. This supports the hypothesis that physical activity can lead to a better psychological climate in which individuals have more cognitive and emotional resources available to regulate eating behavior.

In the context of obesity, both structured (e.g., fitness classes, running) and lifestyle physical activity (e.g., walking for transportation, taking the stairs) have been positively associated with successful long-term weight control [26]. Prior research has suggested that psychological and physiological correlates of different forms of physical activity might be specific, at least to some extent. For instance, Silva et al. [27] found that motivational mechanisms underlying the adoption of structured exercise differed from those associated with lifestyle physical activity in overweight women. Baldwin and Courneya [28] reported positive associations between strenuous exercise and physical self-perceptions, but not for mild to moderate intensities; and Carraça et al. [19] observed that structured exercise was more strongly associated with body image improvement during weight management, while lifestyle physical activity was more associated with the prevention of its deterioration in the longer term. However, very few studies have looked at these differences so far.

This study examined whether negative body image investment and depressive mood mediated the relation between physical activity and critical markers of eating self-regulation (fig. 1) at the end of a weight management intervention (12 months). Secondly, it explored whether these mediational relations were stable, by repeating the analysis at 36 months. 
Based on our previous research [19, 29], we predicted that the mediating effects through body image investment would be more marked for structured rather than lifestyle physical activity. On the contrary, current evidence does not allow to draw any clear conclusions about the effect of different forms of exercise on depressive mood [24]; thus, no specific predictions concerning distinct mediating paths through this variable were made. Mediations were expected at both time points and to get clearer as the intervention effect became more distant.

\section{Material and Methods}

\section{Study Design and Intervention}

This study was conducted in the context of a longitudinal randomized controlled trial consisting of a 12-month behavior change intervention and a 24-month follow-up period that was primarily focused on increasing exercise self-motivation and exercise adherence, aiming at long-term weight control. Participants were randomly assigned to intervention and control groups. The intervention group participated in 30 sessions for approximately 12 months, directed at increasing physical activity and energy expenditure, adopting a moderately restricted diet, and ultimately establishing exercise and eating patterns that would support weight maintenance. The intervention was based on self-determination theory [30,31] with a special focus on increasing self-regulation and competence toward exercise and weight control, while supporting participants' autonomous decisions as to which changes they wanted to implement and how. The comparison group received a general health education curriculum. A detailed description of the study's theoretical rationale, protocol, and intervention strategies can be found elsewhere [32]. The Ethics Committee of the Faculty of Human Kinetics of the Technical University of Lisbon reviewed and approved the study.

\section{Participants}

Participants were recruited from the community at large through web and media advertisements. Inclusion criteria required participants to be pre-menopausal 25- to 50-year-old women with a BMI between 25 and $40 \mathrm{~kg} / \mathrm{m}^{2}$ who were free from major illnesses and not taking medication known to interfere with weight regulation. Of all women who entered the study $(\mathrm{n}=258), 37$ were subsequently excluded from all analyses because they started taking medication (e.g., antidepressants, antiepileptics) susceptible of affecting weight $(n=13)$, were diagnosed with serious chronic diseases or severe illness/injury $(n=4)$, became pregnant $(n=11)$ or entered menopause $(n=9)$. These 37 women were of similar age $(\mathrm{p}=0.737)$ and BMI $(p=0.852)$ as the 221 participants considered as the valid initial sample.

The effective sample was between 23 and 50 years old (37.6 \pm 7 years), and overweight or mildly obese (initial BMI $31.6 \pm 4.1 \mathrm{~kg} / \mathrm{m}^{2}$ ). They were relatively well educated, with $67 \%$ having at least some college education; $56 \%$ of the women were married. Women in the intervention group did not differ from those in the control group in terms of BMI, age, education, or marital status. There were also no differences between the women who completed the 12-month $(n=208)$ and 36-month $(n=156)$ assessments and those who quit the program, for any demographics or baseline psychosocial variable, with the exception of age; women who stayed in the program until the 36-month assessments were, on average, 3 years older at the start of the program $(p=0.05)$. All participants signed a written informed consent prior to participation in the study.

\section{Measurements}

Physical Activity

To assess structured physical activity, minutes per week of leisure-time moderate and vigorous physical activities were estimated with the 7-Day Physical Activity Recall [33]. Habitual activities with a metabolic equivalent (MET) value above 2.9 and performed during the last 7 days were quantified to produce this variable. Daily lifestyle activity was evaluated with a Lifestyle Physical Activity Index [34] specifically developed for this study. To calculate this index we used a score based on 7 questions ('Using stairs or escalators'; 'Walking instead of using transportation'; 'Parking away from destination'; 'Using work 
breaks to be physically active'; 'Choosing to stand up instead of sitting'; 'Choosing hand work instead of mechanical/automatic'; 'Choosing to be physical active whenever possible'), rated on a 5-point Likert-type scale $(\alpha=0.84)$.

\section{Eating Self-Regulation}

In the current study, eating self-regulation referred to aspects known to positively influence weight management, namely high flexible cognitive restraint, reduced susceptibility to disinhibition, and reduced perceived hunger. The Three-Factor Eating Questionnaire (TFEQ) [35] was used to measure flexible cognitive restraint, disinhibition, and perceived hunger. Flexible restraint (e.g., 'While on a diet, if I eat food that is not allowed, I consciously eat less for a period of time to make up for it'; Cronbach's $\alpha=0.73$ ) represents a more gradual approach to eating and weight control, as opposed to a rigid, all-or-nothing approach to eating and weight control, and is associated with low emotional and disinhibited eating [36]. Higher scores on this subscale indicate greater levels of flexible restraint. Disinhibition refers to an uncontrolled overconsumption of food in response to a variety of stimuli, such as situational and emotional states (e.g., 'Sometimes when I start eating, I just can't seem to stop'; Cronbach's $\alpha>0.84$ ). Perceived hunger refers to the extent to which respondents experience feelings and perceptions of hunger in their daily lives (e.g., 'I get so hungry that my stomach often seems like a bottomless pit'; Cronbach's $\alpha>0.84$ ). Lower scores on both of these subscales represented lower disinhibition and perceived hunger (and a healthier eating regulation).

\section{Psychological Measures}

Body image investment refers to the cognitive-behavioral importance of appearance to one's personal life and sense of self and is characterized by a dysfunctional, excessive preoccupation and effort devoted to the management of appearance, as opposed to a more adaptive valuing and managing of one's appearance [13]. Negative body image investment was assessed with the Body Shape Questionnaire (BSQ) and the Social Physique Anxiety Scale (SPAS). The BSQ [37] is a 34-item instrument scored on a 6-point Likert-type scale (Cronbach's $\alpha=0.97$ ) used to evaluate concerns about weight and shape (e.g., 'Has being naked, such as when taking a bath, made you feel fat?'), and associated cognitive-behavioral consequences (e.g., 'Have you avoided wearing clothes that make you aware of your body?'). Higher values represent greater body shape concerns. The SPAS [38] was used to measure the degree to which people become anxious and concerned when others observe or evaluate their physiques. This scale comprises 12 items (e.g., 'Unattractive features of my physique make me nervous in certain social settings') rated on a 5-point Likert-type scale (Cronbach's $\alpha=0.90$ ). Higher scores represent greater social physique anxiety. Participant's scores on each scale were recoded into a scale ranging from 0 to 100; a composite score reflecting the mean value of the two recoded scales was then calculated for each participant. The Beck Depression Inventory (BDI) [39] is a widely used inventory of the cognitive, affective, and somatic symptoms of depression (e.g., sadness, suicidal ideation, self-criticism). BDI is a 21-item inventory, scored on a 4-point scale, that results in a total score, where higher scores reflect greater depressive symptoms $/$ mood (Cronbach's $\alpha=0.92$ ).

Assessments occurred at the end of the intervention (12 months) and at the end of follow-up (36 months). Participants completed Portuguese versions of all questionnaires cited above. Forward and backward translations between English and Portuguese were performed for all questionnaires. Next, two bilingual Portuguese researchers subsequently reviewed the translated Portuguese versions, and minor adjustments were made to improve grammar and readability. Cronbach's alphas for all measurements were acceptable (above 0.70), except for flexible restraint which was 0.64 [40,41]. These scales were also examined for predictive, convergent and discriminant validity, showing acceptable results [e.g., 16, 29, 40].

\section{Analytical Procedure}

To identify the associations between these variables, absolute scores were used for all analyses. To examine the stability of these associations, analyses were conducted at two different time points: 12 and 36 months. In addition, analyses were performed for all participants (intervention and controls) together. This was done to preserve statistical power and increase the range of possible scores in all measures under analysis, and also because the associations under scrutiny were hypothesized to hold constant regardless of group membership. Still, it is possible that the bivariate relationships between these variables were confounded by the intervention effect, which could have influenced both. Thus, all analyses were further adjusted by group membership (Note: We also considered adjusting for weight change. However, since in 
Carraça et al.: The Association between Physical Activity and Eating Self-Regulation in Overweight and Obese Women

this group weight change was largely covariant with group membership, we thought the risk of overadjustment was also to be considered. To be sure though, data analyses adjusting for weight change were also conducted and led to virtually the same results; thus, they were not reported).

Pearson and partial correlations were used to examine the associations between the study's variables at each time point (12 and 36 months). To examine whether negative body image investment and depressive mood mediated the relationship between physical activity and eating self-regulation, two models were created for each eating-related outcome at both time points: one for structured physical activity and one for lifestyle physical activity (both as independent variables). Yet, before testing mediation, correlation coefficients between independent variables and mediators (path a), and between mediators and dependent variables (path b), were examined. Indirect/mediating effects through each mediator were analyzed only when both paths were significant. Mediation analyses were conducted following the approach of MacKinnon et al. [42], which suggests that mediation can exist even in the absence of a significant relation between the independent $(\mathrm{X})$ and dependent variable $(\mathrm{Y})$. According to these authors, previous approaches such as the causal steps approach have treated the test of the overall relation between $\mathrm{X}$ and $\mathrm{Y}$ as a perfect test of the relation, failing to recognize that this statistical test can have less power than the test of the links in the mediation model in several situations [42], for instance when the sign of the mediated effect, ab, differs from the sign of the direct effect $\left(c^{\prime}\right)$, causing the overall relation of X to $\mathrm{Y}$ (c) to be zero (such cases are known as inconsistent mediation models) [42]. Preacher and Hayes procedures were employed to test mediation [43]. These authors provided an SPSS macro to test the significance of indirect effects (total and specific for each mediator) using both normal theory and bootstrap procedures; yet, the latter are considered preferable because they do not assume normality of the distribution of the indirect effects and hence provide stronger protection against type 2 error compared to normal procedures such as the Sobel test [43]. We report results for both normal theory and bootstrap tests, with a resampling procedure of 5,000 bootstrap samples (biascorrected and accelerated estimates and 95\% confidence intervals (95\% CIs)). Finally, effect ratios were calculated to express the amount of the total effect that is explained by the (total) indirect effects via the mediators. Effect ratios are a preferable (quantitative) way to describe mediated effects, compared to the more common dichotomy of 'full' versus 'partial' definitions [44].

\section{Results}

Retention rates were $93 \%$ and $79 \%$ at 12 months, and $79 \%$ and $62 \%$ at 36 months, for intervention and control groups, respectively. Drop-out reasons included financial/time limitations $(\mathrm{n}=15)$, moving to another city $(\mathrm{n}=4)$, and dissatisfaction with group assignment $(n=1)$; all other women lost to follow-up did not provide a reason $(n=45)$. At the end of the intervention (12 months), average weight change ( $-7.29 \pm 5.93 \%$ vs. $-1.74 \pm 4.96 \%)$ and average levels of structured exercise (300 $\pm 179 \mathrm{~min} /$ week vs. $162 \pm 171 \mathrm{~min} /$ week; $\mathrm{p}<$ 0.001 ) were higher in the intervention groupthan in the control group (), and so were the levels of lifestyle activity ( $3.84 \pm 0.69$ vs. $2.98 \pm 0.81 ; p<0.001$ ) [34]. Between-group differences in eating-related and body image variables were medium to large favoring the intervention group. There were no significant differences for depressive mood. At 36 months, average weight change $(-4.13 \pm 7.75 \%$ vs. $-1.12 \pm 7.20 \%)$ and mean levels of exercise remained higher in the intervention group compared to the control group $(243 \pm 228$ $\mathrm{min} /$ week vs. $142 \pm 158 \mathrm{~min} /$ week, $\mathrm{p}=0.001$ ). A similar pattern was observed for lifestyle physical activity ( $3.43 \pm 0.82$ vs. $3.02 \pm 0.92, p=0.009)$. With the exception of negative body image investment (which remained lower in the intervention group), no other depression- or eating-related differences were found between the two groups.

Table 1 shows bivariate correlations among physical activity, negative body image investment, depressive mood, and eating variables at 12 and 36 months. At the end of the intervention, both lifestyle and moderate/vigorous physical activity were significantly correlated with all eating-related variables. After adjusting for group membership, structured exercise was no longer significantly correlated with eating disinhibition and became only 
Table 1. Bivariate correlations among the study's variables at 12 and 36 months $^{\mathrm{a}}$

\begin{tabular}{|c|c|c|c|c|c|c|c|}
\hline & Structured PA & Lifestyle PA & $\begin{array}{l}\text { Eating } \\
\text { disinhibition }\end{array}$ & $\begin{array}{l}\text { Flexible } \\
\text { restraint }\end{array}$ & Hunger & $\begin{array}{l}\text { Body image } \\
\text { investment }\end{array}$ & $\begin{array}{l}\text { Depressive } \\
\text { mood }\end{array}$ \\
\hline Structured PA & - & $\begin{array}{l}0.39^{* * *} \\
\left(0.25^{* *}\right)\end{array}$ & $\begin{array}{l}-0.18^{*} \\
(-0.10)\end{array}$ & $\begin{array}{l}0.25^{* *} \\
\left(0.17^{\#}\right)\end{array}$ & $\begin{array}{l}-0.21^{* *} \\
\left(-0.18^{*}\right)\end{array}$ & $\begin{array}{l}-0.36^{* * *} \\
\left(-0.25^{* *}\right)\end{array}$ & $\begin{array}{l}-0.16^{*} \\
\left(-0.20^{*}\right)\end{array}$ \\
\hline Lifestyle PA & $\begin{array}{l}0.34^{* * *} \\
\left(0.29^{* *}\right)\end{array}$ & - & $\begin{array}{c}-0.29^{* * *} \\
\left(-0.21^{*}\right)\end{array}$ & $\begin{array}{l}0.41^{* * *} \\
\left(0.35^{* * *}\right)\end{array}$ & $\begin{array}{l}-0.37^{* * *} \\
\left(-0.32^{* * *}\right)\end{array}$ & $\begin{array}{l}-0.20^{*} \\
(-0.001)\end{array}$ & $\begin{array}{l}0.003 \\
(-0.009)\end{array}$ \\
\hline Eating disinhibition & $\begin{array}{l}-0.30^{* * *} \\
\left(-0.30^{* *}\right)\end{array}$ & $\begin{array}{l}-0.36^{* * *} \\
\left(-0.33^{* * *}\right)\end{array}$ & - & $\begin{array}{l}-0.28^{* * *} \\
\left(-0.28^{* *}\right)\end{array}$ & $\begin{array}{l}0.64^{* * *} \\
\left(0.60^{* * *}\right)\end{array}$ & $\begin{array}{l}0.55^{* * *} \\
\left(0.48^{* * *}\right)\end{array}$ & $\begin{array}{l}0.26^{* * *} \\
\left(0.24^{* *}\right)\end{array}$ \\
\hline Flexible restraint & $\begin{array}{l}0.22^{* *} \\
(0.16 \#)\end{array}$ & $\begin{array}{l}0.38^{* * *} \\
\left(0.36^{* * *}\right)\end{array}$ & $\begin{array}{l}-0.36^{* * *} \\
\left(-0.38^{* * *}\right)\end{array}$ & - & $\begin{array}{l}-0.44^{* * *} \\
\left(-0.46^{* * *}\right)\end{array}$ & $\begin{array}{l}-0.30^{* * *} \\
\left(-0.26^{* *}\right)\end{array}$ & $\begin{array}{l}-0.21^{* *} \\
\left(-0.22^{*}\right)\end{array}$ \\
\hline Hunger & $\begin{array}{l}-0.24^{* *} \\
\left(-0.19^{*}\right)\end{array}$ & $\begin{array}{l}-0.34^{* * *} \\
\left(-0.31^{* *}\right)\end{array}$ & $\begin{array}{l}0.66^{* * *} \\
\left(0.65^{* * *}\right)\end{array}$ & $\begin{array}{l}-0.47^{* * *} \\
\left(-0.49^{* * *}\right)\end{array}$ & - & $\begin{array}{l}0.47^{* * *} \\
\left(0.44^{* * *}\right)\end{array}$ & $\begin{array}{l}0.17^{*} \\
\left(0.23^{* *}\right)\end{array}$ \\
\hline Body image investment $\mathrm{t}^{\mathrm{b}}$ & $\begin{array}{l}-0.38^{* * *} \\
\left(-0.37^{* * *}\right)\end{array}$ & $\begin{array}{l}-0.25^{* *} \\
\left(-0.21^{*}\right)\end{array}$ & $\begin{array}{l}0.53^{* * *} \\
\left(0.51^{* * *}\right)\end{array}$ & $\begin{array}{l}-0.24^{* *} \\
\left(-0.20^{*}\right)\end{array}$ & $\begin{array}{l}0.45^{* * *} \\
\left(0.42^{* * *}\right)\end{array}$ & - & $\begin{array}{l}0.35^{* * *} \\
\left(0.37^{* * *}\right)\end{array}$ \\
\hline Depressive mood & $\begin{array}{l}-0.27^{* *} \\
\left(-0.30^{* *}\right)\end{array}$ & $\begin{array}{l}-0.24^{* *} \\
\left(-0.22^{*}\right)\end{array}$ & $\begin{array}{l}0.38^{* * *} \\
\left(0.41^{* * *}\right)\end{array}$ & $\begin{array}{l}-0.21^{* *} \\
\left(-0.20^{*}\right)\end{array}$ & $\begin{array}{l}0.24^{* *} \\
\left(0.21^{*}\right)\end{array}$ & $\begin{array}{l}0.42^{* * *} \\
\left(0.36^{* * *}\right)\end{array}$ & - \\
\hline
\end{tabular}

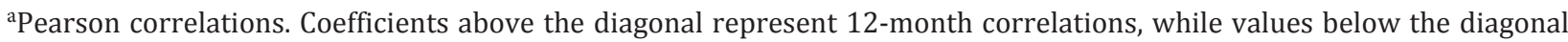
represent 36-month correlations. Coefficients adjusted for group membership are presented inside parenthesis.

${ }^{b}$ Negative body image investment is represented by a composite-score that reflects the level of concern and anxiety related to appearance.

${ }^{\#} \mathrm{p}<0.100 ;{ }^{*} \mathrm{p}<0.05 ;{ }^{* *} \mathrm{p}<0.01 ;{ }^{* * *} \mathrm{p}<0.001$.

weakly related to flexible cognitive restraint $(r=0.17 ; \mathrm{p}=0.050)$. Regarding the associations between physical activity and psychosocial variables, results showed that higher levels of structured exercise were associated with less negative body image investment and depressive mood, before and after adjusting for group membership. On the other hand, lifestyle activity showed associations only with negative body image investment, which disappeared after the adjustment. Depressive mood was not significantly predicted by this type of physical activity. Finally, negative body image investment and depressive mood were consistently negatively associated with eating self-regulation, independent of treatment effect. At the end of followup (36 months), the pattern of associations among these variables was similar, more pronounced and clearer in many cases. The correlation coefficient between structured exercise and eating disinhibition was higher compared to the 12-month coefficient, and remained significant after the adjustment. Additionally, the associations between lifestyle activity and negative body image investment and depressive mood became significant, even after adjusting for group membership.

Next, mediation models were tested. Given that lifestyle physical activity was not correlated with depressive mood at the end of the intervention (12 months), the later variable was not included as a mediator of the lifestyle activity / eating behavior relationships. In these cases, simple mediation models (via body image investment) were tested. The remaining models required multiple mediation tests. 
Carraça et al.: The Association between Physical Activity and Eating Self-Regulation in Overweight and Obese Women

Table 2. 12-month mediation analysis ${ }^{\mathrm{a}}$

Coefficient SE $\quad \begin{aligned} & \text { Normal } \\ & \text { theory p }\end{aligned} \quad$ Bootstrap 95\% CI $\quad$ Effect ratio $\operatorname{Model~R}^{2}$ (p)

\section{Flexible Restraint}

Structured PA

Total effect

Direct effect

Indirect effects (via mediators)

Body image investment

Depressive mood

Lifestyle PA

Total effect

Direct effect

Indirect effects (via mediators)

Body image investment

Depressive mood

$\begin{array}{lllll}0.226 & 0.076 & 0.004 & - & - \\ 0.117 & 0.078 & 0.136 & - & - \\ 0.109 & 0.036 & 0.002 & (0.050 ; 0.212) & 0.48 \\ 0.081 & 0.033 & 0.014 & (0.028 ; 0.165) & 0.36 \\ 0.028 & 0.019 & 0.147 & (-0.003 ; 0.109) & 0.12 \\ & & & & - \\ 0.408 & 0.074 & <0.001 & - & - \\ 0.367 & 0.074 & <0.001 & - & 0.10 \\ 0.041 & 0.022 & 0.064 & (0.009 ; 0.115) & 0.10 \\ 0.041 & 0.022 & 0.064 & (0.009 ; 0.115) & \end{array}$

$0.14(<0.001)$

$0.21(<0.001)$

0.10

\begin{tabular}{|c|c|c|c|c|c|c|}
\hline \multicolumn{7}{|l|}{ Eating disinhibition } \\
\hline Structured PA & & & & & & $0.30(<0.001)$ \\
\hline Total effect & -0.189 & 0.083 & 0.025 & - & - & \\
\hline Direct effect & 0.017 & 0.076 & 0.822 & - & - & \\
\hline Indirect effects (via mediators) & -0.206 & 0.051 & $<0.001$ & $(-0.304 ;-0.123)$ & 1.00 & \\
\hline Body image investment & -0.191 & 0.050 & $<0.001$ & $(-0.294 ;-0.111)$ & 1.00 & \\
\hline Depressive mood & -0.015 & 0.017 & 0.378 & $(-0.065 ; 0.019)$ & 0.08 & \\
\hline \multicolumn{6}{|l|}{ Lifestyle PA } & $0.31(<0.001)$ \\
\hline Total effect & -0.284 & 0.077 & $<0.001$ & - & - & \\
\hline Direct effect & -0.190 & 0.069 & 0.006 & - & - & \\
\hline Indirect effects (via mediators) & -0.093 & 0.040 & 0.021 & $(-0.173 ;-0.025)$ & 0.33 & \\
\hline Body image investment & -0.093 & 0.040 & 0.021 & $(-0.173 ;-0.025)$ & 0.33 & \\
\hline Depressive mood & not tested & & & & & \\
\hline \multicolumn{6}{|l|}{ Perceived hunger } & $0.25(<0.001)$ \\
\hline \multicolumn{7}{|l|}{ Structured PA } \\
\hline Total effect & -0.210 & 0.079 & 0.009 & - & - & \\
\hline Direct effect & -0.036 & 0.075 & 0.613 & - & - & \\
\hline Indirect effects (via mediators) & -0.174 & 0.045 & 0.001 & $(-0.277 ;-0.097)$ & 0.83 & \\
\hline Body image investment & -0.163 & 0.045 & 0.002 & $(-0.264 ;-0.087)$ & 0.78 & \\
\hline Depressive mood & -0.011 & 0.016 & 0.487 & $(-0.056 ; 0.021)$ & 0.05 & \\
\hline \multicolumn{6}{|l|}{ Lifestyle PA } & $0.28(<0.001)$ \\
\hline Total effect & -0.358 & 0.073 & $<0.001$ & - & - & \\
\hline Direct effect & -0.285 & 0.068 & $<0.001$ & - & - & \\
\hline Indirect effects (via mediators) & -0.073 & 0.033 & 0.025 & $(-0.154 ;-0.020)$ & 0.20 & \\
\hline Body image investment & -0.073 & 0.033 & 0.025 & $(-0.154 ;-0.020)$ & 0.20 & \\
\hline Depressive mood & not tested & & & & & \\
\hline
\end{tabular}

${ }^{a}$ For consistency with coefficients (and p values) for total and direct effects, coefficients and standard errors shown for indirect effects are relative to normal theory calculations. However, bootstrap 95\% CIs are preferably interpreted in the text (see Material and Methods for more details).

\section{2-Month Mediation Models}

Table 2 summarizes results for the 12-month mediation analyses. For structured physical activity, results showed that lower negative body image investment was the only significant mediator, explaining between $36 \%$ and $100 \% *$ of the total effect of structured physical activity on eating-related variables (*Note: An effect ratio of 1.00 is observed when the total effect of $\mathrm{X}$ on $\mathrm{Y}$ is somewhat smaller than the indirect effect (through the mediators), and the 
direct effect holding the mediator constant is of the opposite sign, but near zero and far from statistical significance. In these cases, data can be considered consistent with total mediation [44]). Regarding the models for lifestyle physical activity, effect ratios were smaller, indicating that $10-33 \%$ of the effects of lifestyle activity on eating behavior were explained by reduced negative body image investment. An examination of the variance explained $\left(R^{2}\right)$ by these models appears to indicate that flexible eating restraint is the marker of eating behavior least affected by structured exercise $\left(R^{2}=0.14\right)$. On the other hand, this appears to be the eating variable more strongly related to lifestyle physical activity.

Additional tests of mediation were conducted controlling for group membership. For structured exercise models, indirect/mediated effects through lower negative body image investment remained significant. The following $95 \%$ CIs were obtained for flexible restraint $(0.007 ; 0.128)$, eating disinhibition $(-0.221 ;-0.050)$, and perceived hunger $(-0.203 ;-0.040)$. Depressive mood was again a non-significant intervening variable among all the tested associations. For the lifestyle physical activity models, no indirect/mediated effects were found for either marker of eating self-regulation. An increase in the direct effects of lifestyle activity on each eating-related variable was observed instead.

\section{6-Month Mediation Models}

36-month mediation analyses allowed a clearer view of the specific associations between physical activity and each eating-related variable (table 3). Regarding both flexible eating restraint models, none of the mediators was significant by itself. Even so, structured exercise effects on flexible restraint were no longer significant after the inclusion of both mediators in the model, suggesting that the cumulative effect of exercise-induced reductions in negative body image investment and depressive mood partially mediated this relationship, explaining $40 \%$ of the total effects of structured physical activity on flexible restraint. For eating disinhibition, results were similar for the structured and lifestyle activity models, with both putative mediators being identified as significant. Accordingly, effect ratios of 0.69 and 0.43 were found for the significant (total) indirect effects in each model, indicating that $69 \%$ and $43 \%$ of the total effects of each respective type of exercise on eating disinhibition was explained by the two mediators. Body image specific indirect effects amounted to $52 \%$ and $28 \%$ of the total effects of structured and lifestyle physical activity on eating disinhibition. Regarding perceived hunger models, results showed that negative body image investment was the only significant mediator, explaining $64 \%$ and $27 \%$ of the total effect of structured and lifestyle physical activity on hunger. Additional tests of mediation controlling for group membership were conducted and produced similar results.

\section{Discussion}

Successful weight management relies heavily on eating and exercise behaviors. However, little is known about their association at a psychosocial level. This study sought to fill this gap, by examining whether negative body image investment and depressive mood were potential mediators of the relation between physical activity (structured and lifestyle activity) and improved eating regulation (increased flexible restraint, reduced disinhibition, and perceived hunger). As hypothesized, the relationship between self-reported physical activity and eating regulation was mediated by negative body image investment and, to a smaller degree, by depressive mood (for most eating variables). This suggests that, besides physiological effects of exercise possibly related to increased energy expenditure and homeostatic appetite regulation, psychological mechanisms may also support the role of physical activity as a 'gateway behavior' for improved eating self-regulation. In addition, these effects remained evident (or 
Carraça et al.: The Association between Physical Activity and Eating Self-Regulation in Overweight and Obese Women

Table 3. 36-month mediation analysis ${ }^{\mathrm{a}}$

\begin{tabular}{|c|c|c|c|c|c|c|}
\hline & Coeffici & SE & $\begin{array}{l}\text { Normal } \\
\text { theory p }\end{array}$ & Bootstrap 95\% CI & Effect ratio & Model R ${ }^{2}(\mathrm{p})$ \\
\hline \multicolumn{7}{|l|}{ Flexible Restraint } \\
\hline Structured PA & & & & & & $0.09(0.003)$ \\
\hline Total effect & 0.216 & 0.078 & 0.006 & - & - & \\
\hline Direct effect & 0.130 & 0.084 & 0.123 & - & - & \\
\hline Indirect effects (via mediators) & 0.086 & 0.035 & 0.019 & $(0.018 ; 0.175)$ & 0.40 & \\
\hline Body image investment & 0.056 & 0.025 & 0.110 & $(-0.012 ; 0.149)$ & 0.26 & \\
\hline Depressive mood & 0.030 & 0.048 & 0.217 & $(-0.033 ; 0.109)$ & 0.14 & \\
\hline Lifestyle PA & & & & & & $0.17(<0.001)$ \\
\hline Total effect & 0.365 & 0.081 & $<0.001$ & - & - & \\
\hline Direct effect & 0.314 & 0.084 & $<0.001$ & - & - & \\
\hline Indirect effects (via mediators) & 0.052 & 0.029 & 0.075 & $(-0.004 ; 0.128)$ & 0.14 & \\
\hline Body image investment & 0.022 & 0.023 & 0.352 & $(-0.014 ; 0.086)$ & 0.06 & \\
\hline Depressive mood & 0.030 & 0.023 & 0.200 & $(-0.029 ; 0.119)$ & 0.08 & \\
\hline \multicolumn{7}{|l|}{ Eating disinhibition } \\
\hline Structured PA & & & & & & $0.32(<0.001)$ \\
\hline Total effect & -0.299 & 0.076 & $<0.001$ & - & - & \\
\hline Direct effect & -0.094 & 0.073 & 0.198 & - & - & \\
\hline Indirect effects (via mediators) & -0.205 & 0.048 & $<0.001$ & $(-0.308 ;-0.125)$ & 0.69 & \\
\hline Body image investment & -0.154 & 0.042 & $<0.001$ & $(-0.249 ;-0.088)$ & 0.52 & \\
\hline Depressive mood & -0.051 & 0.025 & 0.038 & $(-0.106 ;-0.012)$ & 0.17 & \\
\hline Lifestyle PA & & & & & & $0.37(<0.001)$ \\
\hline Total effect & -0.358 & 0.084 & $<0.001$ & - & - & \\
\hline Direct effect & -0.204 & 0.076 & 0.008 & - & - & \\
\hline Indirect effects (via mediators) & -0.153 & 0.050 & 0.002 & $(-0.257 ;-0.069)$ & 0.43 & \\
\hline Body image investment & -0.099 & 0.040 & 0.012 & $(-0.199 ;-0.038)$ & 0.28 & \\
\hline Depressive mood & -0.053 & 0.027 & 0.047 & $(-0.123 ;-0.014)$ & 0.15 & \\
\hline Perceived hunger & & & & & & $0.21(<0.001)$ \\
\hline \multicolumn{7}{|l|}{ Structured PA } \\
\hline Total effect & -0.239 & 0.078 & 0.003 & - & - & \\
\hline Direct effect & -0.071 & 0.078 & 0.365 & - & - & \\
\hline Indirect effects (via mediators) & -0.164 & 0.044 & $<0.001$ & $(-0.267 ;-0.092)$ & 0.69 & \\
\hline Body image investment & -0.153 & 0.043 & $<0.001$ & $(-0.254 ;-0.087)$ & 0.64 & \\
\hline Depressive mood & -0.014 & 0.022 & 0.511 & $(-0.081 ; 0.042)$ & 0.06 & \\
\hline Lifestyle PA & & & & & & $0.25(<0.001)$ \\
\hline Total effect & -0.336 & 0.084 & $<0.001$ & - & - & \\
\hline Direct effect & -0.236 & 0.082 & 0.005 & - & - & \\
\hline Indirect effects (via mediators) & -0.101 & 0.041 & 0.013 & $(-0.192 ;-0.027)$ & 0.30 & \\
\hline Body image investment & -0.092 & 0.038 & 0.016 & $(-0.186 ;-0.033)$ & 0.27 & \\
\hline Depressive mood & -0.009 & 0.021 & 0.650 & $(-0.075 ; 0.052)$ & 0.03 & \\
\hline
\end{tabular}

${ }^{a}$ For consistency with coefficients (and p values) for total and direct effects, coefficients and standard errors shown for indirect effects are relative to normal theory calculations. However, bootstrap 95\% CIs are preferably interpreted in the text (see Material and Methods for more details).

became significant, in the case of depressive mood) 24 months after the end of the intervention, indicating that exercise-induced changes in psychological markers of eating behavior may also explain why physical activity plays such a key role in long-term weight management, as consistently witnessed in the literature [26]. This study's results give further empirical support to Baker and Brownell's model (outlined in the introduction) and extend prior 
Carraça et al.: The Association between Physical Activity and Eating Self-Regulation in Overweight and Obese Women

research $[5,7]$ by suggesting that exercise-induced improvements in negative body image investment and to a lesser extent depressive mood may also generalize to other weight loss behaviors, allowing for an improved capacity to regulate eating.

Our findings appear to indicate that negative body image investment might be a more critical mediating mechanism in the exercise-eating relationship compared to depressive mood, at least for this population. At the end of the intervention (12 months), reduced body image dysfunctional investment was the only significant mediator of this relation, in some cases explaining over $75 \%$ of the positive effects of physical activity on eating variables; at 36 months, although (lower) depressive mood emerged as a significant mediator of the exerciseeating relationship, negative body image investment continued to explain a greater portion of the indirect effects of exercise on eating behavior. The preponderant role of negative body image investment is not surprising considering the current social environment. Many overweight people present a negative body image [10], probably due to the high emphasis modern culture places on the pursuit of a slim body ideal and due to the high stigmatization and discrimination levels towards obesity [45]. Those seeking treatment, such as women represented in the current sample, are particularly vulnerable to excessive appearance-related concerns [46]. Furthermore, improving appearance and body image are often primary motives to lose weight reported by obese individuals [47]. Thus, it is only natural that this study's participants are more sensitive to changes in this particular psychosocial variable, even though the intervention curriculum included strategies to attenuate the attentional salience attributed to appearance-related issues. In addition, while positive effects of exercise on body image appear to be consistent [17], a recent Cochrane review suggested that the improvement in depressive symptoms following physical activity participation remains inconsistent [48]. Furthermore, the causal role of poor body image as antecedent/precursor of maladaptive eating behaviors has been consistently reported in the literature [11-13]. On the other hand, the causal nature of the association between depressive mood and eating behavior is not clearly established in the literature as depressive mood may be a cause [21] or an effect of maladaptive eating [49].

Two forms of physical activity were analyzed in this study. As expected, the relationship between structured exercise and eating behavior was more strongly mediated by negative body image investment and depressive mood than the relation between lifestyle activity and eating behavior. As also hypothesized, lifestyle activity showed higher direct (not mediated) associations with all eating variables, especially flexible restraint. These findings are in line with our previous work $[19,29]$ and appear to support prior research, suggesting that mild to moderate exercise intensities might not be enough to induce changes in psychosocial variables such as body image [28, 50]; instead, moderate to vigorous activities appear to be required. Additionally, our results suggest that other mechanisms might explain the association between lifestyle activity and eating behavior (especially with flexible cognitive restraint). Motivational factors, such as self-efficacy or internally regulated motivation, might also underlie the effects of exercise on eating behavior as prior research has shown [5, 8]. Annesi and Marti [8] confirmed that increases in exercise self-efficacy would influence eating self-efficacy and dietary compliance, and Mata et al. [5] observed that autonomous motivation mediated the effects of physical activity on eating self-regulation. Small changes in daily life activities, such as parking further away from the destination or regularly taking the stairs, are unlikely to carry the physiological significance needed to affect mood-stabilizing neurotransmitters, but because they can be integrated more easily and with less effort into one's daily routine they might generate an increased sense of mastery and competence, which might generalize to other weight loss behaviors such as eating. Furthermore, women who effectively internalize the motivation to be more physically active in such a way that they automatically (and consistently) prefer the more active option over the more sedentary behavior 
(e.g., standing instead of sitting when waiting), may also display a more internal and stable motivation (i.e., personally meaningful in the sense that it is strongly aligned with core values) to adopt other behaviors related to weight management, such as eating behavior.

Our results indicate that the indirect effects of exercise on eating behavior through reductions in negative body image investment and depressive mood are relatively stable, since they continue to exist after some time. Also, the intervening role of these psychological variables on the lifestyle activity-eating relationship, as well as the mediating role of depressive mood (in general) became clearer at 36 months, possibly due to the dissipation of the intervention effect. The 12-month group-adjusted analyses appear to offer some support for the presence of suppression effects by the intervention, in particular when lifestyle physical activity is involved. This intervention covered the topics of eating regulation and body image to a considerable extent [32]; thus it does not surprise that the effects of lifestyle physical activity on eating and body image variables are masked (i.e., reduced or concealed) by the intervention.

This study is not without limitations. It was based on a post-hoc analysis of a randomized controlled trial not specifically designed to study the association between exercise and eating behaviors. Although originating from a randomized controlled trial, these data were analyzed cross-sectionally at two different time points preventing us from drawing firm conclusions about the causal direction of the associations. Naturally, the possibility of reverse causality cannot be excluded. Statistical analyses were adjusted for group membership, but we might not have been able to completely remove the effects of treatment. Nevertheless, even at 36 months, when these effects appeared less plausible, data analyses were also performed with the adjustment; results were similar before and after the adjustment, offering greater confidence to the present findings. The generalizability of the results in this study may be limited to overweight and obese women seeking treatment, a population that is particularly prone to body image disturbances, weight preoccupation, and dysfunctional eating patterns. Future studies specifically planned to study these associations and able to overcome at least some of the current limitations are needed to confirm or refute these findings. Nevertheless, this study suggests that the relationship between physical activity and eating regulation might be, at least in part, explained by psychological mechanisms such as reduced negative body image investment and (to a lesser extent) depressive mood. If confirmed, our results clearly contribute to explain why physical activity appears to be such a critical element for successful long-term weight management.

\section{Acknowledgements}

This study was funded by grants from the Portuguese Science and Technology Foundation (FCT-PTDC/ DES/114867/2009 and SFRH/BD/40937/2007 to the first author) and the Calouste Gulbenkian Foundation (grant number 65565/2004). The authors are grateful to the Oeiras City Council, Nestlé Portugal, and IBESA for their additional financial support.

\section{Disclosure Statement}

The authors have no conflict of interest to disclose. 
Carraça et al.: The Association between Physical Activity and Eating Self-Regulation in Overweight and Obese Women

\section{References}

1 Flegal KM, Carroll MD, Odgen CL, Curtin LR: Prevalence and trends in obesity among US adults, 1999-2008. J Am Med Assoc 2010;303:235-241.

-2 do Carmo I, Dos Santos O, Camolas J, Vieira J, Carreira M, Medina L, Reis L, Myatt J, Galvao-Teles A: Overweight and obesity in Portugal: national prevalence in 2003-2005. Obes Rev 2008;9:11-19.

-3 Jeffery RW, Drewnowski A, Epstein LH, Stunkard AJ, Wilson GT, Wing RR, Hill DR: Long-term maintenance of weight loss: current status. Health Psychol 2000;19:5-16.

4 Martins C, Morgan L, Truby H: A review of the effects of exercise on appetite regulation: an obesity perspective. Int J Obes (Lond) 2008;32:1337-1347.

5 Mata J, Silva MN, Vieira PN, Carraça EV, Andrade AM, Coutinho SR, Sardinha LB, Teixeira PJ: Motivational 'spillover' during weight control: increased self-determination and exercise intrinsic motivation predict eating self-regulation. Health Psychol 2009;28:709-716.

6 Baker CW, Brownell KD: Physical activity and maintenance of weight loss: Physiological and psychological mechanisms; in Bouchard C (ed): Physical Activity and Obesity. Champaing, Human Kinetics; 2000, pp 311-328.

7 Annesi JJ, Unruh JL: Relations of exercise, self-appraisal, mood changes and weight loss in obese women: testing propositions based on Baker and Brownell's (2000) model. Am J Med Sci 2008;335:198-204.

-8 Annesi JJ, Marti CN: Path analysis of exercise treatment-induced changes in psychological factors leading to weight loss. Psychol Health 2011;26:1081-1098.

-9 Faith MS, Butryn M, Wadden TA, Fabricatore A, Nguyen AM, Heymsfield SB: Evidence for prospective associations among depression and obesity in population-based studies. Obes Rev 2011;12:e438-e453.

-10 Schwartz MB, Brownell KD: Obesity and body image. Body Image 2004;1:43-56.

11 Pelletier LG, Dion SC: An examination of general and specific motivational mechanisms for the relations between body dissatisfaction and eating behaviors. J Soc Clin Psychol 2007;26:303-333.

12 Stice E: Risk and maintenance factors for eating pathology: a meta-analytic review. Psychol Bull 2002;128: 825-848.

13 Cash TF, Melnyk SE, Hrabosky JI: The assessment of body image investment: an extensive revision of the appearance schemas inventory. Int J Eat Disord 2004;35:305-316.

14 GoldschmidtAB, Hilbert A, Manwaring JL, Wilfley DE, Pike KM, Fairburn CG, Striegel-Moore RH: The significance of overvaluation of shape and weight in binge eating disorder. Behav Res Ther 2010;48:187-193.

15 Brannan ME, Petrie TA: Psychological well-being and the body dissatisfaction-bulimic symptomatology relationship: an examination of moderators. Eat Behav 2011;12:233-241.

16 Carraça EV, Silva MN, Markland D, Vieira PN, Minderico CS, Sardinha LB, Teixeira PJ: Body image change and improved eating self-regulation in a weight management intervention in women. Int J Behav Nutr Phys Act 2011;8:75-85.

17 Campbell A, Hausenblas HA: Effects of exercise interventions on body image: a meta-analysis. J Health Psych 2009;14:780-793.

18 Annesi JJ: Effects of minimal exercise and cognitive behavior modification on adherence, emotion change, selfimage, and physical change in obese women. Percept Mot Skills 2000;91:322-336.

19 Carraça EV, Markland D, Silva MN, Coutinho SR, Vieira PN, Minderico CS, Sardinha LB, Teixeira PJ: Physical activity predicts changes in body image during obesity treatment in women medicine and science in sports and exercise. Med Sci Sports Exerc 2012;44:1604-1612.

20 Macht M: How emotions affect eating: a five-way model. Appetite 2008;50:1-11.

-21 Konttinen H, Männistö S, Sarlio-Lähteenkorva S, Silventoinen K, Haukkala A: Emotional eating, depressive symptoms and self-reported food consumption. A population-based study. Appetite 2010;54:473-479.

-22 Spoor ST, Stice E, Bekker MH, Van Strien T, Croon MA, Van Heck GL: Relations between dietary restraint, depressive symptoms, and binge eating: a longitudinal study. Int J Eat Disord 2006;39:700-707.

-23 Carrard I, Crépin C, Ceschi G, Golay A, Van der Linden M: Relations between pure dietary and dietary-negative affect subtypes and impulsivity and reinforcement sensitivity in binge eating individuals. Eat Behav 2011;13: 13-19.

24 Biddle SJ, Mutrie N: Psychology of Physical Activity: Determinants, Well-Being, and Interventions. 2nd ed. London, Routledge, 2008.

-25 Annesi JJ, Vaughn LL: Relationship of exercise volume with change in depression and its association with selfEfficacy to control emotional eating in severely obese women. Adv Prev Med 2011;2011:514271..

-26 Donnelly JE, Blair SN, Jakicic JM, Manore MM, Rankin JW, Smith BK: American College of Sports Medicine Position Stand. Appropriate physical activity intervention strategies for weight loss and prevention of weight regain for adults. Med Sci Sports Exerc 2009;41:459-471.

27 Silva MN, Markland DM, Vieira PN, Coutinho SR, Carraça EV, Palmeira AL, Minderico CS, Matos MG, Sardinha LB, Teixeira PJ: Helping overweight women become more active: need support and motivational regulations for different forms of physical activity. Psychol Sports Exerc 2010;11:591-601.

28 Baldwin MK, Courneya KS: Exercise and self-esteem in breast cancer survivors: An application of the exercise and self-esteem model. J Sport Exerc Psychol 1997;19:347-358.

29 Andrade AM, Coutinho SR, Silva MN, Mata J, Vieira PN, Minderico CS, Melanson KJ, Baptista F, Sardinha LB, Teixeira PJ: The effect of physical activity on weight loss is mediated by eating self-regulation. Patient Educ Couns 2010;79:320-326. 
Carraça et al.: The Association between Physical Activity and Eating Self-Regulation in Overweight and Obese Women

-30 Ryan RM, Deci EL: Self-determination theory and the facilitation of intrinsic motivation, social development, and well-being. Am Psychol 2000;55:68-78.

31 Deci EL, Ryan RM: Intrinsic Motivation and Self-Determination in Human Behavior. New York, Plenum, 1985, pp 113-148.

-32 Silva MN, Markland D, Minderico CS, Vieira PN, Castro MM, Coutinho SR, Santos TC, Matos MG, Sardinha LB, Teixeira PJ: A randomized controlled trial to evaluate self-determination theory for exercise adherence and weight control: rationale and intervention description. BMC Public Health 2008;8:234-246.

-33 Blair SN, Haskell WL, Ho P, Paffenbager RS Jr, Vranizan KM, Farquhar JW, Wood PD: Assessment of habitual physical activity by a seven-day recall in a community survey and controlled experiments. Am J Epidemiol $1985 ; 122: 794-804$.

-34 Silva MN, Vieira PN, Coutinho SR, Minderico CS, Matos MG, Sardinha LB, Teixeira PJ: Using self-determination theory to promote physical activity and weight control: a randomized controlled trial in women. J Behav Med 2010;33:110-122.

-35 Stunkard A, Messick S: The three-factor eating questionnaire to measure dietary restraint, disinhibition and hunger. J Psychosom Res 1985;29:71-83.

-36 Westenhoefer J: Dietary restraint and disinhibition: is restraint a homogeneous construct? Appetite 1991;16: 45-55.

-37 Cooper PJ, Taylor MJ, Cooper Z, Fairburn CG: The development and validation of a body shape questionnaire. Int J Eating Disord 1987;6:485-494.

38 Hart EA, Leary MR, Rejeski WJ: The measurement of social physique anxiety. J Sport Exerc Psychol 1989;11: 94-104.

-39 Beck AT, Steer RA, Garbin MG: Psychometric properties of the Beck Depression Inventory - 25 years of evaluation. Clin Psychol Rev 1988;8:77-100.

40 Teixeira PJ, Silva MN, Coutinho SR, Palmeira AL, Mata J, Vieira PN, Carraca EV, Santos TC, Sardinha LB: Mediators of weight loss and weight loss maintenance in middle-aged women. Obesity (Silver Spring) 2010;18: 725-735.

-41 Palmeira AL, Branco TL, Martins SC, Minderico CS, Silva MN, Vieira PN, Barata JT, Serpa SO, Sardinha LB, Teixeira PJ: Change in body image and psychological well-being during behavioral obesity treatment: associations with weight loss and maintenance. Body Image 2010;7:187-193.

42 MacKinnon DP, Fairchild AJ: Current directions in mediation analysis. Curr Dir Psychol Sci. 2009;18:16-20.

43 Preacher KJ, Hayes AF: Asymptotic and resampling strategies for assessing and comparing indirect effects in multiple mediator models. Behav Res Methods 2008;40:879-891.

44 Shrout PE, Bolger N: Mediation in experimental and nonexperimental studies: new procedures and recommendations. Psychol Methods 2002;7:422-445.

45 Puhl RM, Heuer CA: The stigma of obesity: a review and update. Obesity (Silver Spring) 2009;17:941-964.

46 Sarwer DB, Wadden TA, Foster GD: Assessment of body image dissatisfaction in obese women: specificity, severity, and clinical significance. J Consult Clin Psychol 1998;66:651-654.

47 Sarwer DB, Thompson JK, Cash TF: Body image and obesity in adulthood. Psychiatr Clin North Am 2005;28: 69-87.

-48 Mead GE, Morley W, Campbell P, Greig CA, McMurdo M, Lawlor DA: Exercise for depression. Cochrane Database Syst Rev 2009;3:CD004366.

49 Pelletier LG, Dion SC, D'Angelo MS, Reid RD: Why do you regulate what you eat? Relationships between forms of regulation, eating behaviors, sustained dietary behavior change, and psychological adjustment. Motiv Emot 2004;28:245-277.

-50 Thögersen-Ntoumani C, Fox KR, Ntoumanis N: Testing the mediating role of physical acceptance in the relationship between physical activity and self-esteem: an empirical study with Danish public servants. Eur J Sport Sci 2002;2:1-10. 